\title{
Maskengeschichtliches Potpourri
}

\section{Jann Schwarzenbach}

Dr. med., Facharzt für Allgemeinmedizin, Mitglied FMH

Dr. Carnevale konnte sich für den eigenen Nachnamen nie so richtig erwärmen. Das hatte durchaus nachvollziehbare Gründe: In seinen Berner Jugendjahren gab es keine nennenswerte Fasnacht, zum Basler Morgenstreich wäre er wohl stets zu spät gekommen, und «Drei rüüdige Tage» in Luzern endeten kläglich im äthyltoxischen Filmriss. Schlussendlich vergällten ihm dann die notorisch rezidivierenden Tessiner Karnevalsprügeleien die allerletzte Lust auf närrische Maskeraden. Im nachfolgenden Berufsleben kam er

\section{Ohne nähere Präzisierung war dieser Satz} angesichts asymptomatischer Virenschleuderer kaum zu verstehen.

aber dennoch ums Mund-Nase-Schützen nicht herum: so etwa als chirurgischer Hakenhalter oder in der roten Phase der Schweinegrippehysterie. Selbst im täg-

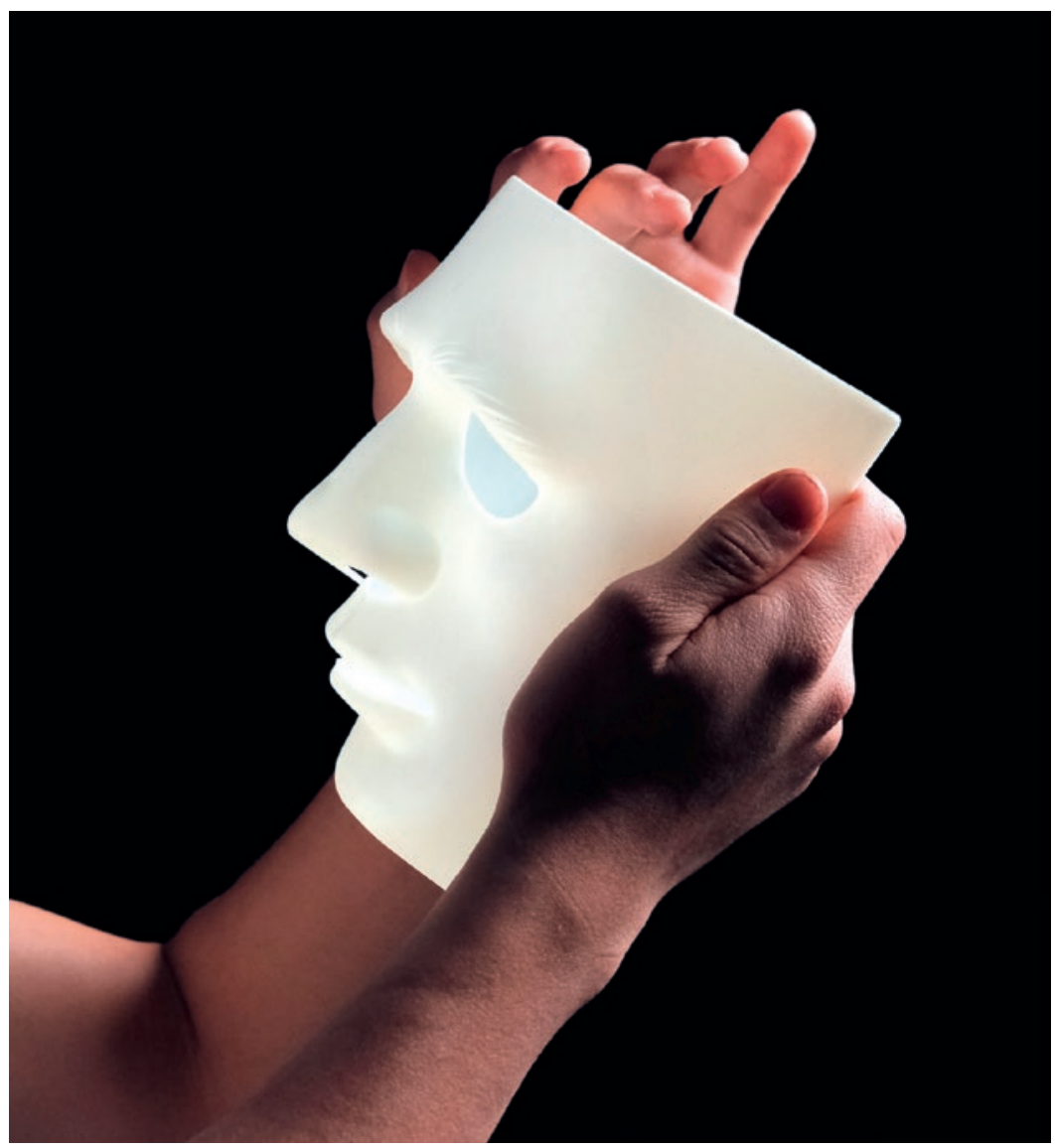

lichen Umgang mit Mitarbeitenden, Patientinnen und Patienten hatte er manchmal das Gefühl, eine Art Maske zu tragen. Diese kaschierte zwar nicht seine Gesichtszüge, aber sein jeweiliges Missbehagen angesichts der Rolle, in die ihn die praxislogischen Arbeitsverhältnisse zwängten: die des selbstsicheren Chefs oder jene des immer aufgestellten Ansprechpartners für Erkrankte und deren Angehörige. Solche Masken liessen sich nicht so einfach wieder ablegen. Dr. Carnevale spürte, dass sie allmählich zum festen Bestandteil des eigenen Ichs wurden und angestammte Inhalte seines Seins damit in den Hintergrund drängten.

\section{Behördliches Sprachchaos}

In der Morgenröte von Covid-19 wurde dann die Maskenfrage so richtig virulent. Die Anzahl einschlägiger Meinungen übertraf die weltweite Verfügbarkeit von Schutzmaterialien und führte so zu einem behördlichen Sprachchaos: «Gesunde brauchen im öffentlichen Raum keine Masken zu tragen.» Ohne nähere Präzisierung war dieser Satz angesichts herumspazierender, asymptomatischer Virenschleuderer wirklich kaum zu verstehen. Bevor man etwas aussagt, sollte man halt nicht nur das Richtige meinen, sondern genauer wissen, wovon man effektiv spricht. Dies gilt auch für Masken, deren allgemeine Bedeutung sich keineswegs in ihrer fraglichen, antipandemischen Leistungsfähigkeit erschöpft. Dr. Carnevale fand diese Behauptung einer näheren Untersuchung wert und beschloss daher, sich diesbezüglich ein wenig schlau zu machen.

\section{Deine Maske - dein Charakter}

Schon mehr als 2000 Jahre vor Covid-19 gab es in den antiken Theatern eine Art Maskenpflicht. Grund dafür war aber kein Virus, sondern die "Persona», eine zur Schallverstärkung unverzichtbare, trichterförmig verlängerte Gesichtsbedeckung. Mit Hilfe verschiedener, zur jeweiligen Rolle passender Personae versteckten sich die Schauspieler gleichsam hinter den Figuren, die sie auf der Bühne darzustellen hatten. Ähnliche faziale Verkleidungen fanden später als sogenannte Charaktermasken ihren Weg in die mitteleuropäische Theaterwelt. Karl Marx (1818-1883) benutzte dann diesen Bühnenbegriff zur überspitzten Kennzeichnung öko- 
nomischer Gesellschaftsklassen, wie etwa Grundbesitzer, Unternehmer oder Lohnarbeiter. Da nun jedermann notwendigerweise die Charaktermaske der eigenen sozialen Gruppe tragen müsse, sei niemand für sein gesellschaftliches Fehlverhalten persönlich verantwortlich zu machen. Mit der Demaskierung und

\section{Unser bewusst erfahrenes Ich sei nur eine Maske, die wir aufsetzten, um unserer gesell- schaftlichen Rolle gerecht zu werden.}

Beseitigung einzelner Funktionsträger schaffe man daher noch lange keine gerechten Zustände. Diese würden sich aber - und das ohne jegliches individuelle Dazutun - im Werdegang der Geschichte ganz von selbst einstellen. Einschlägige Linksextreme haben diese unmissverständliche, optimistische Aussage ihres Lieblingsphilosophen böswillig ignoriert.

\section{Sexuelle Dimensionen}

Im Gegensatz zu Marx liegt für Carl Gustav Jung (18751961) der Schlüssel zum geglückten Leben nicht in einer utopischen Staatsform, sondern in der Fruchtbarmachung verborgener, innerer Ressourcen. Unser bewusst erfahrenes Ich sei in Wahrheit nur eine oberflächliche Maske, die wir aufsetzten, um unserer ge-

Den nötigen Schwung liefere die Libido, eine kreative Naturkraft, deren geistige Dimension den kruden sexuellen Appetit übersteige.

sellschaftlichen Rolle nach aussen hin gerecht zu werden. Dabei vernachlässigten wir verdrängte, unbewusste Seeleninhalte, ohne die wir gewissermassen nur halbe Menschen seien. Für seinen hassgeliebten aber wohl originelleren - Übervater Sigmund Freud war das Unterbewusstsein bekanntlich ein suspektes Versteck individueller Sexualnöte. Jung hingegen lo- kalisierte da vor allem eine Heimstätte traditionell überlieferter Archetypen: eine Art strukturelle Urbilder möglicher Weltvorstellungen, die allen Menschen gemeinsam innewohnen würden. Diese seien für ein voll ausgebildetes Selbst unabdingbar und würden uns dabei helfen, unser Umfeld menschengerecht zu gestalten. Den nötigen Schwung dazu liefere die Libido, eine kreative Naturkraft, deren geistige Dimension den kruden sexuellen Appetit bei weitem übersteige.

\section{Eine virale Fasnachtsparty}

Während die grossen Psychologen des vorigen Jahrhunderts ihre Fangnetze durch die Tiefen der Seele schleiften, lauern zeitgenössische, gut maskierte "Phischer» auf den digitalen Oberflächen unbedarfter Userinnen und User. Dabei geht es nicht nur um eindeutig kriminelle Akte. Auch im durchaus legalen Marketing ist das Ausspionieren der Eigenschaften, Vorlieben und Verhaltensweisen typischer Kundengruppen - sogenannter "Personae» - gang und gäbe. Mit diesem linguistischen Link zur antiken Theaterwelt möchte Dr. Carnevale sein maskengeschichtliches Potpourri abschliessen. Die Maskenfrage bleibt aber eine «affaire à suivre» - insbesondere im Hinblick auf eine nächstwinterliche, zweite Covid-19-Welle. Im letzten Februar stieg im Tessin noch eine virenbombige Fasnachtsparty, und jetzt, im Nachhinein, ist Dr. Carnevale natürlich froh um seine lebensgeschichtlich bedingte Immunität gegenüber solchen Festlichkeiten. Sonst hätte er sich womöglich angesteckt. Dazu braucht es aber natürlich immer noch eine Portion schicksalhaftes Pech. Eines ist aber alles andere als unwahrscheinlich: Eine einfache Gesichtsmaske hätte das wohl kaum verhindern können.

\section{Bildnachweis}

c) Roman Volskiy | Dreamstime.com 